\title{
The relationship between the subclinical target organ damage and the levels of ischemia-modified albumin in hypertensive patients
}

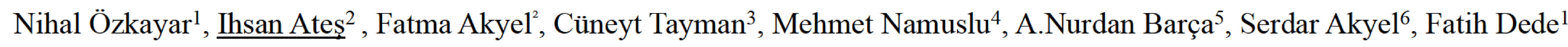

${ }^{1}$ Ankara Numune Education and Research Hospital, Department of Nephrology, Ankara, Turkey

${ }^{2}$ Ankara Numune Education and Research Hospital, Department of Internal Meicine, Ankara, Turkey

${ }^{3}$ Denizli Goverment Hospital, Department of Neonatology , Denizli, Turkey.

${ }^{4}$ Turgut Ozal University Medical School, Department of Medical Biochemistry, Ankara, Turkey.

${ }^{5}$ Ankara Numune Education and Research Hospital, Department of Radiology, Ankara, Turkey

${ }^{6}$ Ankara Numune Education and Research Hospital, Department of Cardiology, Ankara, Turkey

\section{Objectives:}

Hypertension (HT) is an important and rectifiable risk factor for cardiovascular, renal and cerebral diseases. Constantly high blood pressure in hypertensive patients causes structural and functional changes, referred to as target organ damage, in a variety of tissues and organs, particularly the cardiovascular system. Proteinuria, increased carotid intima-media thickness (CIMT), grade 3-4 retinopathy, and increased left ventricular mass index (LVMI) are all subclinical target organ damage (STOD) indicators of HT.

To investigate the relationship between the presence of subclinical target organ damage (STOD) and the levels of ischemia-modified albumin (IMA) in hypertensive patients.

\section{Methods:}

The study included a total of 106 patients, 53 with STOD and 53 without STOD. STOD was deemed present if fundus examination revealed a grade 3-4 retinopathy; the left ventricular mass index (LVMI) was $>95 \mathrm{~g} / \mathrm{m}^{2}$ in females and $>115 \mathrm{~g} / \mathrm{m}^{2}$ in males at echocardiography; carotid intimal media thickness (CIMT) was $\geq 0,9 \mathrm{~mm}$; and 24 -hours urine had $30-300 \mathrm{mg}$ albumin. IMA levels were assessed by spectrophotometric method using albumin cobalt binding test. All patients underwent ambulatory blood pressure monitoring (ABPM) for 24-hours.

\section{Results:}

The mean whole-day systolic blood pressure was higher in patients with STOD $(128.19 \pm 15.9$ vs $118.55 \pm 10.5$, respectively $P=0.001$ ). The mean diastolic blood pressure was similar in both of the groups $(P>0.05)$. The mean IMA level was higher in patients with STOD $(0.63 \pm 0.09$ vs $0.53 \pm 0.1$ respectively $P=0.013$ ).

Conclusions:

Elevated IMA in patients with STOD is consistent with the role of ischemia and oxidative stress in development of target organ damage in hypertensive patients, and suggests that IMA can be used as an indicator to predict the presence of STOD.

\section{References:}

1. Taverna M, Marie AL, Mira JP, Guidet B. 2013. Specific antioxidant properties of human serum albumin. Annals of intensive care 3(1):4.

2.Bourdon E, Blache D. 2001. The importance of proteins in defense against oxidation. Antioxidants \& redox signaling 3(2):293-311.

3. Chan B, Dodsworth N, Woodrow J, Tucker A, Harris R. 1995. Site-specific N-terminal auto-degradation of human serum albumin. European journal of biochemistry / FEBS 227(1-2):524-528. 